Rev. CAP Jurídica Central N. 4 - agosto 2019, ISSN 2550-6595

\title{
DESCENTRALIZACIÓN EN ECUADOR ¿UN PROCESO INCONCLUSO? ${ }^{12}$
}

\author{
KARINA PATRICIA TELLO TORAL ${ }^{3}$ Y \\ ÁNGEL GIOVANY LUCIO VÁSQUEZ ${ }^{4}$ \\ UnIVERSIDAD CENTRAL DEL ECUADOR, QUITO-ECUADOR \\ DOCENTES DE PREGRADO Y POSGRADO
}

\section{RESUMEN:}

La presente investigación analizó el proceso de descentralización en el Ecuador, período 2008 - 2018 a partir de dos paradigmas: el primero, la división político administrativa actual; y, el segundo,

1 Artículo entregado por los autores el 15 de marzo de 2019 y aprobado el 25 de junio de 2019

2 Tipo de artículo: Artículo de reflexión. Línea de investigación: Nueva organización territorial y procesos de transferencia de competencias. Investigador principal: Karina Tello Toral, coinvestigador Giovany Lucio.

Abogada de la Pontificia Universidad Católica del Ecuador, Maestría Derecho Público por la U.P.M.F Grenoble II, Cursante del Doctorado en Derecho Constitucional en la Universidad de Buenos Aires. Docente de pregrado y posgrado en la Universidad Central del Ecuador. Correo: kptello@uce.edu.ec. ORCID: https://orcid. org/0000-0003-3444-151X

Licenciatura en Ciencias Políticas, Maestría en Estudios Internacionales por la Universidad de París VIII. Maestría en Gobernanza Europea por Science Po Grenoble. Docente de Derecho Político, y Derecho Internacional en la Universidad Central del Ecuador. Correo: https:/ / orcid.org/0000-0003-2289-292X

4 Catedrático de Derecho Internacional de la Universidad Central del Ecuador. orcid.org/0000-0003-2289-292X 
el proceso de transferencia de competencias en cada uno de los niveles de gobierno. En cuanto a la metodología se utilizan los métodos sistemático y analítico aplicados al campo de las ciencias sociales. La investigación concluye estableciendo que el proceso de descentralización a partir de la Constitución de 2008 es un avatar inconcluso.

\section{PALABRAS CLAVE:}

Gobiernos Autónomos Descentralizados, niveles de gobierno, competencias, organización territorial, descentralización.

\section{ABSTRACT:}

This research analyzes the process of decentralization in the Republic of Ecuador during the 2008 - 2018 period through the structuring of two paradigms: first, the current administrative political division, and second, the process of competences in each one of the levels of government. Regarding the methodology in this proposal, are used the systematic and analytical methods applied to the field of Social Sciences. The investigation concludes stating that the process of decentralization from the Political Constitution of 2008 is an unfinished avatar.

\section{KEY WORDS:}

Decentralized autonomous governments, levels of government, competencies, territorial organization, decentralization. 


\section{Introducción}

La descentralización se entiende como un sistema políticoadministrativo del Estado ${ }^{5}$, en el cual, el objetivo principal es la transferencia de competencias de decisión y gestión hacia los gobiernos locales. Así pues, las razones que han permitido este traspaso se evidencian en el orden político y económico. Primero, en lo referente a las relaciones de poder, el gobierno central se reserva sus competencias regalianas y cede a las colectividades locales ciertas competencias específicas como respuesta a las necesidades del territorio ${ }^{6}$. En consecuencia, el gobierno central se concentra en adoptar directrices, lineamientos y políticas nacionales, mientras que, los gobiernos subnacionales aplican las mismas en el territorio a través de políticas públicas locales.

Segundo, las causas económicas que permitieron el desarrollo de la descentralización son variadas, tanto en su origen como en el espacio, así pues, la puesta en marcha de la ideología neoliberal durante la década de los noventa permitió la consecución de una tercera globalización de orden financiero, lo cual conlleva una deslegitimación del rol del estado en torno a la gobernabilidad de la sociedad, es decir, está ideología pretendía infundir una práctica política y económica que permita el libre desarrollo de

5 La legitimidad de la descentralización está ligada al desarrollo local que dispone de un mecanismo no sólo técnico sino político, pues está ligado al individuo y al territorio.

6 En otras palabras, según EPSTEIN, el Estado organiza su retirada de los territorios para gobernar de mejor manera a distancia y restaurar su autoridad (2015). EPSTEIN, RENAUD. “La gouvernance territoriale: une affaire d'État. La dimension verticale de la construction de l'action collective dans les territoires", en L'Année sociologique. v. 65, N. ${ }^{\circ}$, 2015, pp. 457-482. 
las capacidades y libertades empresariales del individuo para preservar un marco institucional mínimo de regulación ${ }^{7}$. En consecuencia, la imposición ideológica neoliberal en los centros de poder mundial y posteriormente en la periferia ocasionó que el Estado se desligue de funciones planificadoras en torno a la producción, distribución y consumo de bienes y servicios que permitiría al mercado auto regularse sin intromisión estatal. De lo referido, los defensores de la descentralización encontraron un marco propicio para solicitar un traspaso de mejores prácticas desde los territorios, puesto que el Estado sufría un proceso de desmantelamiento.

Por tanto, las causas económicas y políticas se sintetizaron en el proceso denominado globalizacion, el cual marcó Europa y América Latina de manera distinta y permitió la incorporación de la descentralización como parte de una nueva ideología de renovación del Estado.

Es así que en el marco de la consolidación de la Unión Europea, la adopción del tratado de Maastricht suscrito en 1992 consolidó el Mercado Común y permitió la creación de una unidad económica y monetaria ${ }^{8}$. De esta realidad, los Estados establecieron una

7 En el proceso de la tercera globalización surge a partir de la aplicación de la ideología neoliberalismo, la cual permitió la restructuración del Estado, en base a una reducción de competencias (Deng Xiaoping, Paul Volcker, Margaret Thatcher y Ronald Reagan).

8 Si bien en Europa el proceso de descentralización surge en los años de posguerra en Alemania e Italia, y se crean los Landers y regiones autónomas respectivamente. Por otro lado en Francia con el fin de enmendar las exacciones cometidas por el estado central, el país galo en los años 80 comienza el proceso de descentralización. En este sentido, según François Mitterrand en un discurso realizado el 
relación privilegiada hacia las colectividades locales para protegerlas del proceso de globalización y establecer la puesta en marcha de políticas públicas ${ }^{9}$ europeas para subsanar impactos de desindustrialización ${ }^{10}$ y promoción de empresas locales en el seno de las regiones, por tanto, estas entidades regionales comenzaron a tomar una importancia cada vez mas creciente en la estructura política de la UE.

En tanto que, en América Latina el proceso de descentralización se origino a partir de factores distintos; en efecto, el referido cambio no fomento políticas de apaciguamiento frente a la globalización como sus pares en Europa a través de la transferencia de competencias y desarrollo de políticas públicas locales desde el estado nación y la UE, sino que este conglomerado geográfico se insertó desde un paradigma de subordinación a las fuerzas económicas mundiales representadas por el Fondo Monetario Internacional y el Banco Mundial para reducir la intervención

15 de julio de 1981 señaló que: Francia tuvo que centralizarse para constituirse como nación y ahora necesita descentralizarse para no deshacerse. Por otro lado, en Europa se establece la política regional europea para permitir la convergencia y la competitividad regional y empleo, mediante varias políticas o fondos estructurales para evitar el desequilibrio territorial.

9 El paquete Delors II intensificó la política de cohesión, duplicando los recursos para las regiones de los nuevos integrantes de la UE, además se integra como un organismo consultivo de la UE, que disponen de voz directa en el proceso de integración. Además, uno de los fondos estructurales, denominado Fondo de Desarrollo (FEDER), es exclusivo para fomentar el desarrollo equilibrado de distintas regiones. Todos estos Fondos forman parte de los Fondos Estructurales y de Inversión Europeos.

10 El Fondo Social Europeo permite financiar formaciones para adquirir nuevos conocimientos y hacer frente a los cambios bruscos de la desindustrialización en grandes zonas industriales. 
del Estado en ámbitos potencialmente prometedores para los inversionista como son los recursos naturales, banca, electricidad, agua potable y telecomunicaciones ${ }^{11}$.

En efecto, la legitimidad del Estado en los años 80 y 90 sufrió un duro golpe a su estructura, como consecuencia de una crisis de gobernabilidad debido en gran parte a la ineficacia de una política fallida de industrialización añadida a la burocracia creciente e inoperante. En el caso ecuatoriano, la crisis del Estado ocurrió por un proceso de ingobernabilidad producto del excesivo endeudamiento durante los años ochenta y noventa ${ }^{12}$ que conllevó al incumplimiento de los pagos de la deuda externa y de procesos inflacionarios a causa de la reducción del precio del petróleo.

En consecuencia, el estado central ecuatoriano como ente planificador se vió afectado por sus anteriores decisiones rentistas, lo cual ocasionó que el nuevo gobierno democrático en la década de los ochenta busque en el proceso de descentralización: i) el desarrollo del territorio a partir del estímulo de áreas deprimidas,

11 Es interesante percibir que durante la década de los noventa, el FMI estableció la suscripción de Acuerdos Bilaterales de Promoción y Protección Recíproca de Inversiones. En el ámbito global, se encuentran el antecedente del proyecto del Acuerdo Multilateral de Inversiones (AMI), los acuerdos multilaterales de la Ronda Uruguay de la Organización Mundial del Comercio (OMC), el sistema de instituciones afiliadas al Banco Mundial (BM) y la normativa emergente del Convenio constitutivo del Fondo Monetario Internacional (FMI). Granato y Odone. 2007.

$12 \mathrm{Al}$ existir recursos financieros internacionales debido al alto costo del petróleo de los años 70, el Ecuador al ser un país petrolero podía garantizar el pago de la deuda que tomó para industrializar al país durante el proceso de planificación de la dictadura. 
así como ii) la distribución de recursos ${ }^{13}$ y servicios a nivel nacional, en contra peso a la anterior política de los años setenta que privilegiaba el desarrollo de centros urbanos como espacios de industrialización: Quito (centro político) y Guayaquil (centro económico - importaciones y exportaciones).

De esta manera, la Constitución ecuatoriana del año de 1979 estableció una descentralización administrativa y una desconcentración nacional, empero la Codificación de 1996 que reformó la Constitución original del año 1979 añadió varios artículos sobre los regímenes seccionales autónomos dotándolos de autonomía funcional, administrativa y económica. Sin embargo, según Villavicencio, no pasó de ser una simple declaración retórica, sin ninguna incidencia real en la organización territorial estatal y sus prácticas.

Empero, esta norma sirvió de base para la expedición de varios cuerpos legales que impulsaron la descentralización, entre ellos la Ley de Modernización, Privatizaciones y Prestación de Servicios Públicos de 1993; la Ley de Descentralización y Participación Social; la Ley Especial de distribución del 15\% del gobierno central para los gobiernos seccionales y su Reglamento expedidos en 1997.

Posteriormente, la Constitución Política de 1998 (CPE, 1998) establece que todas las competencias son descentralizables, bajo un esquema voluntario para gobiernos autónomos seccionales y de obligatoriedad para el gobierno central ${ }^{14}$. Así pues, este

13 Constitución Política del Ecuador. Decreto Supremo 000, Registro Oficial 800, 27 de marzo de 1979, (Art. 118 28). Impreso.

14 Art. 226 de la Constitución Política del Ecuador, de 1998, establecía: 
sistema se denominó de manera peyorativa como competencias a la carta, puesto que los gobiernos seccionales solicitaban al gobierno central competencias de acuerdo a sus intereses, lo cual ocasionó diferencias en la repartición de competencias y la correspondiente miríada de situaciones.

Esta Constitución Política de 1998 sirvió de marco para la adopción de normas como la Ley Orgánica de las Juntas Parroquiales Rurales; el Reglamento a la Ley de Descentralización del Estado y Participación Social y Plan Nacional de Descentralización; y más tarde, la Ley Orgánica de Régimen Municipal. En consecuencia, estas normas legales convirtieron a los municipios en los actores principales del proceso de descentralización.

Finalmente, la Constitución de 2008 (CRE, 2008) establece que las competencias son descentralizables bajo un esquema obligatorio y progresivo (Art. 239 46), así el Código Orgánico de Organización Territorial, Autonomía y Descentralización (COOTAD) define a la descentralización como la transferencia obligatoria, progresiva y definitiva de competencias con los respectivos talentos humanos y recursos financieros, materiales y tecnológicos, desde el gobierno central hacia los gobiernos autónomos descentralizados (Art. 105 33). En conclusión, la entrega de competencias de la Constitución Política de 1998 muta desde una voluntad de los GADs en asumirlas hasta una obligatoriedad en su puesta en práctica y progresividad en su entrega a partir de la Constitución Política de 2008.

"La descentralización será obligatoria cuando una entidad seccional la solicite y tenga capacidad operativa para asumirla". COOTAD, (Art. 68). 
En el presente artículo se analizará, si el proceso de descentralización ha promovido la organización territorial y las transferencias de competencias hacia los GADs durante el período 2008-2018.

El objetivo general de la presente investigación es identificar la existencia de una eficaz organización territorial y transferencias de competencias durante el proceso de descentralización en el período 2008-2018.

Para lo cual, en el presente trabajo se analizará la descentralización en torno a: A) la división político administrativa actual; y, B). El proceso de transferencia de competencias en cada uno de los niveles de gobierno.

En cuanto a la metodología a utilizar se aplicarán los métodos: por un lado, el sistémático, el cual partiendo del análisis de los componentes, medio y estructura sobre la cual opera la descentralización de competencias en los distintos niveles de gobernabilidad del Estado permitirá tener una comprensión sistémica del orden o reglas establecidas. Por otro, se utilizará el método analítico, que consistirá en la desmembración de la organización territorial y sus distintas competencias frente la norma que regula su comportamiento, esto a fin de identificar causas, naturaleza y efectos provocados con su aplicación. Este método además, permitirá conocer el objeto de estudio planteado, para finalmente extraer conclusiones sobre como la norma ha impactado a la sociedad y su realidad en la actualidad. 


\section{ORGANIZACIÓN TERRITORIAL EN PROCESO DE CONFORMACIÓN}

La descentralización es un proceso permanente, el cual, mantiene una estrecha relación con la estructuración de la organización territorial denominada tradicionalmente como división político administrativa. En efecto, en el plano legal la CRE, 2018 propuso una variación en cuanto a la organización territorial en relación a la CP, 1998, así pues, la Tabla 1 explica esta evolución:

\section{Tabla I.}

Cuadro comparativo de la organización territorial ecuatoriana y sus regímenes especiales.

\begin{tabular}{|c|c|c|c|}
\hline Situación & $\begin{array}{c}\text { Constitución de } \\
1998\end{array}$ & $\begin{array}{c}\text { Constitución de } \\
2008\end{array}$ & Análisis \\
\hline $\begin{array}{l}\text { Organización } \\
\text { Territorial }\end{array}$ & $\begin{array}{l}\text { - Provincias } \\
\text { - Cantones } \\
\text { - Parroquias Rurales }\end{array}$ & $\begin{array}{l}\text { - Regiones } \\
\text { - Provincias } \\
\text { - Cantones } \\
\text { - Parroquias } \\
\text { Rurales }\end{array}$ & $\begin{array}{l}\text { Se aumentan las } \\
\text { regiones como } \\
\text { nueva forma de } \\
\text { organización te- } \\
\text { rritorial, aunque } \\
\text { aún no se han } \\
\text { constituido. }\end{array}$ \\
\hline $\begin{array}{l}\text { Régimen Especial } \\
\text { - Forma de } \\
\text { gobierno diferente } \\
\text { dentro de las } \\
\text { organizaciones } \\
\text { territoriales. }\end{array}$ & $\begin{array}{l}\text { - Circunscripciones } \\
\text { territoriales } \\
\text { de pueblos y } \\
\text { nacionalidades } \\
\text { indígenas } \\
\text { - Distritos } \\
\text { Metropolitanos } \\
\text { - Islas Galápagos } \\
\text { (Instituto Nacional } \\
\text { Galápagos ) }\end{array}$ & $\begin{array}{l}\text { - Circunscripciones } \\
\text { territoriales de } \\
\text { nacionalidades y } \\
\text { pueblos indígenas } \\
\text { - Distritos } \\
\text { Metropolitanos } \\
\text { - Islas Galápagos }\end{array}$ & $\begin{array}{l}\text { No se han } \\
\text { constituido hasta } \\
\text { ahora Distritos } \\
\text { Metropolitanos } \\
\text { autónomos, ni } \\
\text { circunscripciones } \\
\text { territoriales } \\
\text { de pueblos y } \\
\text { nacionalidades } \\
\text { indígenas. }\end{array}$ \\
\hline
\end{tabular}

Elaboración propia

Fuente: CPE, 1998 y CRE, 2008

Tabla 1 datos comparativos 
El cuadro comparativo establece diferencias, tanto en la creación de la región como nueva estructura así como una inexistente constitución de la misma. De esta manera, la región forma parte una nueva organización territorial sin que se encuentre aún constituida, lo mismo ocurre con las circunscripciones territoriales de pueblos y nacionalidades indígenas como regímenes especiales, que a pesar de haber sido establecida su creación en la anterior CP, 1998 aún no se han materializado. Finalmente, en este mismo orden de ideas, a partir del año 2008, los Distritos Metropolitanos requieren nuevos requisitos para su conformación, lo que ha dado como resultado que ningún distrito metropolitano autónomo se haya constituido.

\subsection{Regiones como nueva forma de organización territorial}

En la CRE, 2008 se estableció que la organización territorial ecuatoriana se conformaría por regiones, provincias, cantones y parroquias rurales (Art.242 46). Así pues, la región se iza como nueva forma de organización territorial, aunque, una imagen concomitante puede ser percibida a inicios de la República, pues se estableció en 1830 un antecedente a partir de la existencia de tres departamentos, sin embargo, desde 1835 con Vicente Rocafuerte como Presidente, hasta el año 2008, la organización territorial únicamente estuvo conformada por provincias, cantones y parroquias ${ }^{15}$.

15 En la Constitución de 1830 se estableció: "El territorio del Estado se divide en departamentos (Quito, Guayaquil y Cuenca), provincias, cantones y parroquias". (Art. $5312 \mathrm{CPE}$ )

En la Constitución de 1835 se estableció: "El territorio de la República se divide en provincias, cantones y parroquias...". Esta organización territorial estuvo vigente hasta la Constitución de 1998, siendo la Constitución de 2008 la nueva organización. (Art. 82 17) 
Así pues, la creación de regiones surgió con el ánimo de hacer frente de manera grupal a los desafíos que enfrentan los conglomerados territoriales, los cuales presuponen fortalezas como: identidad cultural, solidaridad técnica y presupuestaria entre provincias y correlación de sistemas ecológicos ${ }^{16}$. Por lo tanto, el nuevo paradigma buscaba superar las diferencias y desigualdades en el territorio ecuatoriano (equilibrio interterritorial) ${ }^{17}$, en donde el desarrollo económico ha sido bicentralista (Quito y Guayaquil), además, los territorios organizados horizontalmente, con superficies y poblaciones equivalentes ${ }^{18}$ permite la creación de un Estado policéntrico. ${ }^{19}$

Sin embargo, ésta planificación territorial se quedó en buenas intenciones puesto que hasta la actualidad no se ha conformado ninguna región, primero por una actitud conformista del gobierno Central y segundo por una inacción de los gobiernos provinciales.

16 CRE (Art. 244 46) y COOTAD (Art. 15 8) establecen los criterios para la conformación de regiones.

17 El COOTAD señala: “La organización territorial del Estado y la asignación de competencias y recursos garantizarán el desarrollo equilibrado de todos los territorios, la igualdad de y el acceso a los servicios públicos. (Art 3.f)

18 Dentro de los requisitos que establece el COOTAD, se encuentra i) $20.000 \mathrm{Km} .2$, ii) 5 \% población nacional, en ningún caso una región podrá tener el $20 \%$ del territorio nacional. (Art.15)

19 Empero, la constitución de esta nueva organización territorial ha traído críticas al considerarse como un proceso dirigido por el Gobierno Central, que limitó la conformación de Manabí por sí sola como una región o la conformación de una región Amazónica. Como señala Viciano: "Los criterios identatarios de la población pueden no coincidir con los tecnocráticos del Estado." 
En lo referente al Gobierno Central es menester explicar antecedentes legales que permitieron al Ejecutivo desligarse de la toma de decisión en cuanto a la conformación de regiones:

- En un primer momento, la Disposición Transitoria Primera de la Constitución original de Montecristi establecía en el numeral 9, el plazo para la expedición del COOTAD y al mismo tiempo señalaba que el plazo para la conformación de regiones autónomas en ningún caso excedería el plazo de ocho años.

- El COOTAD en cumplimiento al mandato constitucional estableció en su Disposición Transitoria Tercera que las regiones en ocho años se conformarían por iniciativa de los gobiernos provinciales, empero, si no existía iniciativa de los gobiernos provinciales dentro del referido plazo, el Presidente de la República podía enviar el proyecto de conformación de regiones a la Asamblea Nacional para que el legislativo lo apruebe. Así pues, si el Ejecutivo hubiese conformado las regiones, posiblemente un prospecto serían las zonas de planificación del SENPLADES que se pueden encontrar en el gráfico 1, que actualmente son zonas de desconcentración. 


\section{- $\quad$ Gráfico 1}

\section{Zonas de Planificación Secretaría Nacional de Planificación y}

\section{Desarrollo (SENPLADES)}
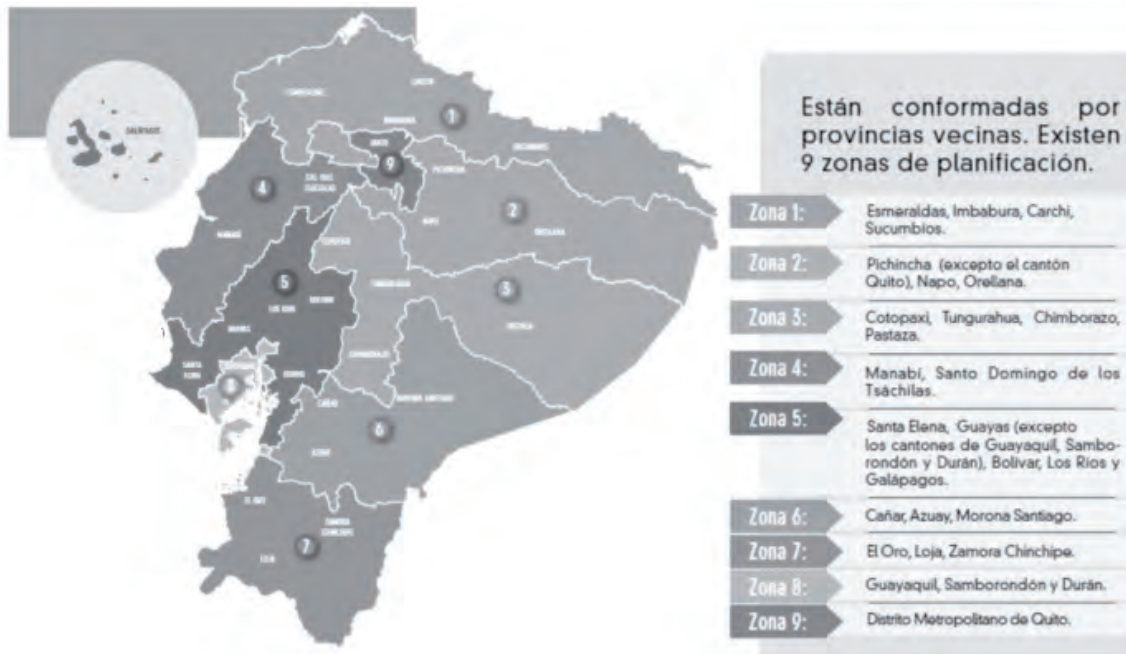

Fuente: Figura en Secretaría Nacional de Planificación y Desarrollo: Quito, Ecuador: Senplades. http://hitcloud.senplades.gob.ec/zona-administrativa-de-planificacion

Sin embargo, el Ejecutivo se desliga de esta facultad de conformar regiones por enmienda constitucional, puesto que, dentro de los primeros cambios que se realizaron a la Constitución original de Montecristi ${ }^{20}$ se eliminó el plazo de 8 años para la conformación de regiones y por ende la iniciativa del Presidente de la República

20 Ecuador. Enmienda a la Constitución de la República del Ecuador de 2015, , Suplemento del Registro Oficial N. 653, 18 de diciembre de 2015. (Art. 15 3). Impreso. 
de constituirlas. Por lo tanto, el órgano legislativo de los gobiernos provinciales será el único órgano que promueva el proceso de creación de región ${ }^{21}$.

De esta manera queda claro, que el Ejecutivo mediante cambio de normativa constitucional se deslindó de su facultad regulatoria en torno a la creación de regiones, puesto que, en el año 2016 se vencía el plazo de 8 años para conformar las regiones por parte del Presidente de la República, así pues, es menester señalar que este cambio fue utilizado como estrategia política, ya que en el 2015 se enmienda la CRE, lo cual permite al Presidente no ser parte del proceso de conformación de regiones. Es evidente, que el año 2016 y 2017 constituyen un período álgido para la continuidad del proceso político de Alianza País, ya que la campaña electoral y las elecciones presidenciales se desarrollaban en este lapso de tiempo, por lo tanto, el Ejecutivo deslinda su responsabilidad ya que no desea abrir frentes que podrían poner en peligro la continuidad del movimiento del poder ${ }^{22}$.

Por otro lado, los gobiernos provinciales no han promovido el proceso de conformación de regiones, puesto que, la creación de éste nivel supra de gobierno debilita las estructuras clientelares

21 Proyecto de Ley se enviará a la Asamblea Nacional, órgano que tiene 120 días para pronunciarse, Estatuto de Autonomía que se enviará a la Corte Constitucional para que en 45 días emita un informe, y finalmente se llamará a consulta popular para que el cuerpo electoral de las provincias se pronuncie a favor o en contra. COOTAD (Art. 16, 8)

22 Con la declaratoria de inconstitucionalidad de las Enmiendas del 2015, la disposición transitoria primera, numeral 1 regresa a su texto original lo que implica que se siguen manteniendo el plazo de 8 años para la conformación de la región. 
que se desarrollan en sus territorios provinciales. En este mismo sentido, el desequilibrio de las poblaciones de las provincias que conforman la región limita un poder de decisión homogéneo en el seno de la región, donde las provincias con mayor densidad poblacional obtendrían mayor poder de decisión que sus pares menores en el órgano legislativo de la región. (COOTAD, Art.33, 2010) Además, otra causa que evita la conformación de regiones es la utilización de mecanismos administrativos como convenios de mancomunidades y consorcios ${ }^{23}$, los cuales representan mayores beneficios sin una pérdida de poder de decisión.

Por último, cabe señalar que el panorama en los siguientes años no es propicio para la conformación de regiones, ya que la situación económica álgida que sufre el país no permite mayores egresos que otorgaría el estado a las regiones. Así pues, según el artículo 244 de la CRE, 2008 se establece que: La ley creará incentivos económicos y de otra índole, para que las provincias se integren en regiones (Art. $46 \mathrm{CRE}$ ). Asimismo, la creación de una región conlleva aumento de burocracia lo cual aumenta el coste de funcionamiento del Estado ${ }^{24}$.

23 La CRE, 2008 señala: Los gobiernos autónomos descentralizados regionales, provinciales, distritales, cantonales o parroquiales rurales y los de las circunscripciones territoriales indigenas, afro ecuatorianas y montuvias podrán formar mancomunidades entre sí, con la finalidad de mejorar la gestión de sus competencias y favorecer sus procesos de integración (...). (Art. 243 46) En tanto que el COOTAD establece que: Las mancomunidades y consorcios que se constituyan podrán recibir financiamiento del presupuesto general del Estado para la obra o proyecto objeto del mancomunamiento (...). (Art. 285 60)

24 El Art. 117 del COOTAD original establecía la participación de las regiones en la recaudación de varios impuesto, con las reformas del COOTAD se deroga el literal a) que corresponde al impuesto a la renta de herencias, donaciones manteniendo la competencia el gobierno 


\section{2. Regímenes Especiales entre continuidad sin materialización}

Los regímenes especiales son formas de gobierno diferentes a sus pares dentro de la organización territorial existente, puesto que, los primeros se constituyen por razones de alta densidad poblacional, relaciones étnico culturales y por motivos de conservación ambiental de territorios vulnerables.

En este marco es necesario efectuar un análisis del tipo de Régimen Especial con sus respectivas características, nivel de territorio y forma de gobierno.

Tabla 2

Cuadro sobre Regímenes Especiales

\begin{tabular}{|c|c|c|c|}
\hline Régimen Especial & $\begin{array}{l}\text { Razones de } \\
\text { Conformación }\end{array}$ & $\begin{array}{c}\text { Nivel dentro de } \\
\text { la organización } \\
\text { territorial }\end{array}$ & $\begin{array}{c}\text { Forma de } \\
\text { Gobierno diferente }\end{array}$ \\
\hline $\begin{array}{c}\text { Distrito } \\
\text { Metropolitano }\end{array}$ & $\begin{array}{l}\text { Alta densidad } \\
\text { poblacional ( } 7 \% \\
\text { población nacional } \\
\text { - población mayor } \\
\text { a la requerida para } \\
\text { conformar una } \\
\text { región). }\end{array}$ & Cantonal & $\begin{array}{l}\text { Gobierno } \\
\text { metropolitano } \\
\text { (podrá asumir } \\
\text { competencias de } \\
\text { región provincia, } \\
\text { cantón dentro de } \\
\text { su circunscripción } \\
\text { territorial) }\end{array}$ \\
\hline Islas Galápagos & $\begin{array}{l}\text { Conservación } \\
\text { Natural }\end{array}$ & Provincial & $\begin{array}{l}\text { Consejo de } \\
\text { Gobierno }\end{array}$ \\
\hline $\begin{array}{l}\text { Circunscripciones } \\
\text { territoriales } \\
\text { de pueblos y } \\
\text { nacionalidades } \\
\text { indígenas }\end{array}$ & Étnico cultural & $\begin{array}{l}\text { Depende de la } \\
\text { población puede } \\
\text { encontrarse en } \\
\text { provincias, cantones } \\
\text { o parroquias. }\end{array}$ & $\begin{array}{l}\text { Libre determinación } \\
\text { de los pueblos }\end{array}$ \\
\hline
\end{tabular}

Elaboración propia

Fuente: Constitución Política de 2008 y COOTAD 2010

central y refleja la actitud de desinterés de fortalecer regiones. 
A partir del cuadro precedente, en las siguientes líneas se analizará cada uno de los regímenes especiales.

\section{2. 1. Distritos Metropolitanos.}

Los distritos metropolitanos como se señaló en el cuadro que precede es un Régimen Especial a nivel cantonal, por razones de alta densidad poblacional. En lo referente a su evolución histórica, la primera Constitución que señala la figura del Distrito Metropolitano (D.M.) es la Constitución de 1979, incluidas las reformas de $1983^{25}$. Posteriormente, en la CPE de 1998 se estableció en su artículo 238 la posibilidad de constituir distritos metropolitanos como un tipo de organización especial por razones demográficas. Asimismo, en la Constitución Política de 2008, en su artículo 242, establece al D.M. como una forma de gobierno diferente que el cantón, con mayores competencias y por ende mayores recursos. Así pues, la creación de los D.M. ya dispone de una historia de cerca de cuatro décadas, sin embargo, una diferencia sustancial es que la norma actual añade al régimen especial de los distritos metropolitanos competencias propias de la región, provincia y cantón en su circunscripción territorial.

Asimismo, la nueva Carta Magna establece los requisitos para la conformación de distritos metropolitanos; el primer elemento que surge es i) el nivel de densidad poblacional, así pues, el porcentaje requerido asciende al $7 \%$ de la población nacional. ii) un proyecto de ley, iii) un estatuto de autonomía y finalmente, iv) una consulta popular.

25 BARRERA, Augusto. (coord). Ecuador un modelo para (des)armar, descentralización, disparidades y modelo de desarrollo. Quito, Abya-Yala 1999. Impreso. 
De esta manera, en lo referente al primer requisito, los únicos cantones que disponen del número poblacional requerido en la República del Ecuador son las ciudades de Quito y Guayaquil. Por ello, en las Zonas de Planificación del SENPLADES que constan en el gráfico 1, siete zonas de planificación se asimilan al concepto de región y dos al concepto de Distrito Metropolitano, sin embargo, en el caso del cantón de Guayaquil se propone la fusión $^{26}$ con los cantones de Samborondón y Durán ${ }^{27}$. En la actualidad no existe ningún Distrito Metropolitano Autónomo completamente constituido, empero, un caso especial constituye el D. M. de Quito, puesto que, la Ley Orgánica del Régimen del Distrito Metropolitano de Quito ${ }^{28}$ de 1993 cumple la función de creación y de delimitación territorial ${ }^{29}$, es decir, ésta norma formaliza el requisito de Ley. Sin embargo, para concluir el proceso de distritalización hace falta la elaboración del Estatuto de Autonomía ${ }^{30}$ y el sometimiento del mismo a consulta popular.

26 Dentro del COOTAD, se establece la posibilidad de fusionarse a los cantones y parroquias rurales y como incentivo, el Gobierno Central beneficiará con una obra a los dos cantones o parroquias fusionadas. (Artículos 23 y 27 del COOTAD)

Los cantones Guayaquil, Samborondón y Durán, dentro de su proceso de crecimiento, han convertido a estos territorios en cantones circunvecinos, donde no se diferencia dónde empieza o termina cada cantón (SUING, p. 39), a pesar que el cantón Guayaquil por sí solo cumple el requisito de población.

Ley Orgánica del Régimen del Distrito Metropolitano de Quito. Registro Oficial N. ${ }^{\circ}$ 345, de 27 de diciembre de 1993

29 Así, en el art. 1 de la Ley de Régimen del Distrito Metropolitano se establece: El cantón al que pertenece la capital de la República se denomina Distrito Metropolitano de Quito." Y en el Art. 5 "El territorio del Distrito Metropolitano de Quito es el mismo que constituye el cantón Quito. (Arts. $1,2)$

30 En el año 2009, el Instituto de la Ciudad presentó un borrador de 
Estos nuevos requisitos que permitirían la conformación del D.M surgen como contraparte a la obtención de mayores competencias asignadas a este régimen especial. Por ello, el cantón Quito está parcialmente constituido como Distrito Metropolitano y por ende no dispone de la capacidad legal para asumir competencias de los GADs regionales y provinciales en su circunscripción territorial $^{31}$.

En conclusión, es menester indicar que los Distritos Metropolitanos, en este caso concreto Quito, devienen procesos inconclusos de descentralización, puesto que no disponen de todos los requisitos necesarios para asumir mayores competencias y por ende mayores recursos técnicos y financieros.

\section{2. 2. Islas Galápagos}

Las Islas Galápagos se establecen como un régimen especial en razón de sus particularidades ambientales y por constituir patrimonio natural de la humanidad ${ }^{32}$. El territorio de Galápagos está administrado por un Consejo de Gobierno, órgano que viene a eliminar al Instituto Nacional de Galápagos (INGALA).

Estatuto de Autonomía ante el Concejo Metropolitano para que éste sea discutido y aprobado por el Concejo Metropolitano, el cual fue promovido por el anterior Alcalde Paco Moncayo. (SUING)

Art. 266 CRE y Art. 73 COOTAD.

32 Las Islas Galápagos fueron inscritas en 1978 como Patrimonio Natural en base a los siguientes criterios: vii) puesto que contiene fenómenos naturales superlativos o áreas de belleza natural; viii) ocho sitios representativos de las etapas más importantes de la historia de la tierra; ix) ser ejemplos eminentemente representativos de procesos ecológicos y biológicos en curso en la evolución; $y, x$ ) hábitats naturales más representativos 
Según la Constitución, éste Consejo de Gobierno estaría integrado por un representante de la Presidencia de la República e integrado por los alcaldes de los municipios de la provincia de Galápagos, y representante de las juntas parroquiales y otros que determine la ley, en este caso, la disposición transitoria vigésima sexta del COOTAD integró a los Ministros del área ambiental, turística y planificación.

Sin embargo, con el surgimiento de la Ley Orgánica de Régimen Especial de la provincia de Galápagos (LOREG) se derogaron las disposiciones transitorias del COOTAD que regulaban este territorio $^{33}$. Así, esta Ley de 2015 reguló la integración del Consejo de Gobierno, que actualmente está conformado por:

1. El representante del Presidente de la República;

2. El Ministro de Ambiente;

3. El Ministro de Turismo;

4. El Ministro de Agricultura, Ganadería y Pesca;

5. SENPLADES;

6. Los alcaldes de los tres cantones de la provincia de Galápagos; y,

7. Un representante permanente de los presidentes de las juntas parroquiales rurales de la provincia de Galápagos. (Art. 10, LOREG).

33 Se derogan las disposiciones transitorias vigésimo sexta, vigésimo séptima, vigésimo octava, vigésima novena y trigésima del COOTAD (2010), que regulaba la conformación, atribuciones del Consejo del Gobierno, atribuciones de la Secretaría Técnica del Consejo de Gobierno de la provincia de Galápagos, recursos económicos de este Consejo, entre otros temas. 
De esta manera, una vez desglosada la composición del Consejo queda demostrado que la mayoría de integrantes representa a la Función Ejecutiva y no a los GADs, a pesar de que su regulación se enmarca de forma macro en el COOTAD y específica en LOREG. Por lo tanto, es menester indicar que el Estado retoma su actitud centralista en post de la salvaguarda de las islas, puesto que los GADs no disponen de los recursos para hacer frente a una problemática internacional de conservación, sobre todo en el tema de seguridad marítima, regulación de turismo, y planificación territorial ${ }^{34}$. Así pues, en lo referente a la normativa internacional ${ }^{35}$, el Estado Parte dispone de legación pasiva para cumplir con las obligaciones emanadas de los tratados internacionales, en este sentido, la política pública debe ser subsidiaria cuando los GADs no pueden cumplir con su cometido y necesitan de la fuerza coercitiva del Estado y la planificación territorial para hacer frente a estos riesgos.

Por lo tanto, la creación de un Consejo de Gobierno en Galápagos busca interrelacionar a los actores del Gobierno Central y a los

34 El Gobierno constituyó de esta manera como un Régimen Especial a Galápagos, puesto que debió hacer frente a la inscripción de las islas en la lista de patrimonios en peligro de la UNESCO, por lo tanto, era necesario implementar Políticas Públicas que permitan una salida de esta lista. Sin embargo, según UNESCO, en su reporte 2018 sobre las Islas Galápagos aún existen factores que afectan al bien patrimonial como son: la pesca ilegal, gobernanza, identidad, cohesión social, actividades ilegales, impactos de turismo, especies invasoras, marco legal y alojamiento.

La República del Ecuador ratificó la Convención para la Protección del Patrimonio Mundial, Cultural y Natural de 1972, la cual obliga a identificar, proteger, conservar, rehabilitar y transmitir a las generaciones futuras el patrimonio cultural y natural situado en su territorio (Art. 4). 
GADs con una supremacía de los primeros. En conclusión, la recentralización en este caso concreto a criterios de los autores deviene una acción positiva del Estado, porque los procesos de descentralización sólo incorporan una arista local y no permiten hacer frente a problemas transnacionales.

\section{2. 3. Circunscripciones territoriales de pueblos y nacionalidades indígenas}

Las circunscripciones territoriales de pueblos y nacionalidades indígenas, afro ecuatorianas y montubias (CTT) son un régimen especial por razones de salvaguarda étnico cultural. En el ámbito histórico, la lucha de los pueblos sobre todo indígena es un largo proceso, sin embargo, las primeras reacciones desde las bases se desarrollan a partir de los años 60 en Cayambe, y posteriormente, en la sierra Central, en los años 90 durante la Conmemoración de la conquista española por parte del Estado. En este marco, los indígenas rechazan está visión colonizadora y consideran que lo que debe conmemorarse es un renacimiento de las culturas ancestrales, así pues, éstas reivindicaciones de orden político, económico y cultural se plasman parcialmente en las constituciones de 1998 y 2008. En el marco político, en lo referente al ámbito territorial, los indígenas pretendían disponer del derecho a la autonomía en sus territorios, es decir, delimitar las normas que regulen sus relaciones sociales, de acuerdo a su propia cosmovisión, en un ámbito geográfico exclusivo, empero, este anhelo no se ha materializado.

En este orden de ideas, es menester indicar que la Asamblea Constituyente del Ecuador de 1997-1998, (70 curules) no dispuso de una fuerte representación indígena en el seno de este órgano deliberativo (Pachacutik, 7 curules), puesto que la 
Constituyente estuvo dominada por la alianza de tres partidos políticos: Partido Social Cristiano (22 curules), Democracia Popular (11 curules) y Frente Radical Alfarista, (5 curules). En este marco de relaciones de poder de derecha, el movimiento indígena ${ }^{36}$ propuso la conformación de autonomías, sin embargo, tras varias negociaciones, se logró la inclusión de CTT como régimen especial, sin llegar a una autonomía stricto sensu.

Así, la CPE de 1998, en el artículo 241 señalaba que: $L a$ organización, competencias y facultades de los órganos de administración de las circunscripciones territoriales indígenas y afro ecuatorianas, serán reguladas por la ley. Empero, la ley que regulaba las CTT no se expidió durante el período 1998-2008 (10 años); es decir, durante diez años no existió la norma inferior que determine el procedimiento, y otras normas para lograr su conformación.

Con estos antecedentes, en la CRE de 2008 continúa con este régimen especial y no cambia de perspectiva, como es el anhelo de ciertos grupos indígenas, en consecuencia, el COOTAD establece el proceso de conformación de las CTT, desde una perspectiva colonial, para lo cual establece ciertos elementos para su conformación: i) la elaboración de un estatuto de funcionamiento, ii) una consulta popular, y iii) a pesar de que no se señala expresamente, este estatuto debe someterse a control de constitucionalidad, como los estatutos de autonomía de la región y del distrito metropolitano.

Empero, en la puesta en marcha de la conformación de este régimen de gobierno se han presentado varias dificultades para su

Partido político Pachakutic, ECUARUNARI y CONFENIAE 
conformación, por ejemplo: i) se optó por un régimen especial en el marco de la propia división política administrativa del Estado, es decir, la conformación de una CTI sólo puede ocurrir dentro de los límites territoriales de una parroquia, un cantón, o una provincia, situación ajena a la realidad y ii) en las CTI regirá el gobierno que corresponda al nivel de gobierno en donde éstas se establezcan. En conclusión, estos requisitos en lugar de ser una solución devienen trabas administrativas para la conformación de las CTI, puesto que este régimen especial no se enmarca en las fronteras de la organización territorial actual, es más, ciertas CTI podrían sobrepasar el territorio de provincias y cantones para unirse a otras divisiones administrativas. En este orden de ideas, la CTI si bien es regulada por autoridad proveniente de estos pueblos y nacionalidades, aún queda sujeta a una división política administrativa actual.

En conclusión, es menester indicar que las CTIs devienen procesos inconclusos de descentralización, puesto que ninguna población indígena, afro ecuatoriana o montubia ha concluido el proceso de conformación y, por ende, no han asumido competencias del nivel de gobierno al que pertenecen, deviniendo en un proceso inconcluso de descentralización. 
Rev. CAP Jurídica Central N. 4 - agosto 2019, ISSN 2550-6595

\section{UN PROCESO DE TRANSFERENCIA DE COMPETENCIAS PARCIAL}

Las competencias según el COOTAD, 2010 son las capacidades de acción de un nivel de gobierno en un sector (Art. 113 34); así pues los sectores se constituyen como áreas de intervención y responsabilidad que desarrolla el Estado. (Art. 109 34) A su vez, los sectores se dividen en privativos, estratégicos y comunes, cada uno de los cuales dispone de un nivel de cierre o de apertura a los niveles de gobierno en el proceso de descentralización.

De esta manera, los sectores privativos disponen de competencias no susceptibles de descentralización, sino que corresponde exclusivamente al Gobierno Central como prerrogativas esenciales del Estado ${ }^{37}$. En un estudio comparativo entre la Constitución de 1998 y 2008 se establece diferencias entre un Estado Neoliberal y un Estado Post keynesiano de orden estructuralista, en efecto, en la Carta Magna expedida en la década de los 90 buscaba un Estado mínimo y esto como corolario de las ideas del Consenso de Washington, a contrario sensu, la Constitución Política de 2008 establece un Estado planificador e inversor ${ }^{38}$, por lo tanto, no es de extrañar que sus competencias sean más amplias sobre todo en temas de salud, educación, seguridad social y vivienda.

37 Seguridad y defensa, relaciones internacionales, planificación nacional, políticas económicas, sector social, recursos naturales. (Art. 261 de la CRE, 2008)

38 La política macro-económica fue desarrollada por el Estado Central en el ámbito tributario, aduanero, arancelario; fiscal y monetario; comercio exterior y endeudamiento. (Art. 261 CRE, 2008). Así pues, permitiendo una demanda desde el Estado, con el fin de establecer políticas distributivas y redistributivas del Estado. 
En cambio, en lo referente a los sectores estratégicos, el COOTAD (2010) señala que: La facultad de rectoría y la definición del modelo de gestión de cada sector estratégico corresponden de manera exclusiva al gobierno central (Art. 111 34), sin embargo, la norma permite que pueda existir una facultad o competencia concurrente con otros niveles de gobierno. El artículo precedente no define claramente cuáles serán las facultades y competencias de los GADs, por lo tanto, se presupone que será la puesta en marcha de la gestión, la cual ya es desarrollada por los gobiernos locales.

Por último, los sectores comunes son aquellos susceptibles de descentralización, así pues, las competencias transferidas a los GADs se enmarcan en este sector. De esta manera, las competencias nacen de la Constitución, el COOTAD y de las Resoluciones del Consejo Nacional de Competencias ${ }^{39}$.

En este sentido, cada uno de los sectores disponen de competencias propias, así pues, a partir de esta relación se establece una clasificación de competencias, en un primer momento, las competencias exclusivas y concurrentes, las cuales dependen de los distintos niveles de gobierno que intervienen en su gestión, así como competencias de orden adicional y residual que dependen de las fases del proceso de transferencia.

39 Dentro de sus competencias se encuentra: organizar e implementar el proceso de descentralización, asignar y transferir las competencias adicionales, determinar las competencias residuales que deban ser transferidas a los gobiernos autónomos descentralizados, y determinar los plazos y procedimientos para su transferencia (Art. 119, Art. 35 COOTAD ). 
Rev. CAP Jurídica Central N. 4 - agosto 2019, ISSN 2550-6595

\section{1. Competencias intrínsecas y compartidas}

\section{1. 1. Titularidad que corresponde a un solo nivel de gobierno}

Las competencias exclusivas de los gobiernos locales son aquellas cuya titularidad pertenece a un solo nivel de gobierno, ${ }^{40} \sin$ embargo, el COOTAD señala que la gestión de estas competencias exclusivas puede realizarse de manera concurrente entre diferentes niveles de gobierno (Art.114 34). En consecuencia, esta ambigüedad derivada de la norma oscurece el sentido de las competencias exclusivas, puesto que si la gestión es concurrente en ningún momento deviene exclusiva.

La Constitución y el COOTAD guardan una relación armoniosa, puesto que el COOTAD transcribe de manera textual lo establecido en la Carta Magna. Así pues, el siguiente cuadro determina las competencias por nivel de gobierno.

40 Noconfundirconlos sectores privativosque establecencompetencias exclusivas del gobierno Central. Estas competencias exclusivas de los GADs se enmarcan dentro del sector común. 
Tabla N. ${ }^{\circ} 3$

\section{Competencias Exclusivas de los GADs}

\begin{tabular}{|c|c|c|c|c|}
\hline Competencia & Región & Provincia & Cantón & $\begin{array}{c}\text { Parroquia } \\
\text { Rural }\end{array}$ \\
\hline $\begin{array}{c}\text { Planificación } \\
\text { del Desarrollo } \\
\text { y de Planes de } \\
\text { Ordenamiento } \\
\text { Territorial } \\
\text { articulados con } \\
\text { otros niveles } \\
\text { de gobierno }\end{array}$ & $\begin{array}{c}\text { Articulada } \\
\text { con el } \\
\text { Gobierno } \\
\text { Central, } \\
\text { provincial, } \\
\text { cantonal y } \\
\text { parroquial }\end{array}$ & $\begin{array}{l}\text { Articulada } \\
\text { con el } \\
\text { Gobierno } \\
\text { Central, } \\
\text { regional, } \\
\text { cantonal y } \\
\text { parroquial }\end{array}$ & $\begin{array}{c}\text { Articulada con } \\
\text { el Gobierno } \\
\text { Central, } \\
\text { regional, } \\
\text { provincial y } \\
\text { parroquial }\end{array}$ & $\begin{array}{c}\text { Articulada } \\
\text { con el } \\
\text { Gobierno } \\
\text { provincial y } \\
\text { cantonal }\end{array}$ \\
\hline Agua & $\begin{array}{l}\text { Gestionar el } \\
\text { ordenamiento } \\
\text { de cuencas } \\
\text { hidrográficas }\end{array}$ & $\begin{array}{l}\text {-Obras en } \\
\text { cuencas y } \\
\text { microcuencas } \\
\\
\text {-Planificar, } \\
\text { construir, } \\
\text { operar y } \\
\text { mantener } \\
\text { sistemas de } \\
\text { riego }\end{array}$ & $\begin{array}{c}\text { Prestación del } \\
\text { servicio público } \\
\text { de agua potable }\end{array}$ & $\begin{array}{l}\text { Gestionar, } \\
\text { coordinar y } \\
\text { administrar } \\
\text { los servicios } \\
\text { públicos } \\
\text { que le sean } \\
\text { delegados. } \\
\text { Vigilar la } \\
\text { calidad de } \\
\text { los servicios } \\
\text { públicos. }\end{array}$ \\
\hline
\end{tabular}


Rev. CAP Jurídica Central N. 4 - agosto 2019, ISSN 2550-6595

\begin{tabular}{|c|c|c|c|c|}
\hline $\begin{array}{c}\text { Uso y } \\
\text { Ocupación del } \\
\text { Suelo }\end{array}$ & $\mathrm{N} / \mathrm{C}$ & $\mathrm{N} / \mathrm{C}$ & $\begin{array}{l}\text { - Control } \\
\text { sobre el uso } \\
\text { y ocupación } \\
\text { del suelo en el } \\
\text { cantón } \\
\text {-Elaborar y } \\
\text { administrar } \\
\text { los catastros } \\
\text { inmobiliarios } \\
\text { urbanos y } \\
\text { rurales; } \\
\text {-Delimitar, } \\
\text { regular, } \\
\text { autorizar y } \\
\text { controlar el uso } \\
\text { de las playas de } \\
\text { mar, riberas y } \\
\text { lechos de ríos, } \\
\text { lagos y lagunas, } \\
\text { sin perjuicio de } \\
\text { las limitaciones } \\
\text { que establezca } \\
\text { la ley; } \\
\text {-Preservar y } \\
\text { garantizar el } \\
\text { acceso efectivo } \\
\text { de las personas } \\
\text { al uso de las } \\
\text { playas de mar, } \\
\text { riberas de ríos, } \\
\text { lagos y laguna }\end{array}$ & $\mathrm{N} / \mathrm{C}$ \\
\hline Sistema Vial & $\begin{array}{l}\text { A nivel } \\
\text { regional }\end{array}$ & $\begin{array}{c}\text { A nivel } \\
\text { provincial }\end{array}$ & $\begin{array}{c}\text { A nivel cantonal } \\
\text { (urbana) }\end{array}$ & $\begin{array}{c}\text { En } \\
\text { coordinación } \\
\text { con los } \\
\text { gobiernos } \\
\text { provinciales }\end{array}$ \\
\hline
\end{tabular}




\begin{tabular}{|c|c|c|c|c|}
\hline $\begin{array}{l}\text { Tránsito y } \\
\text { transporte }\end{array}$ & $\begin{array}{c}\text { Tránsito y } \\
\text { el transporte } \\
\text { terrestre } \\
\text { regional }\end{array}$ & $\mathrm{N} / \mathrm{C}$ & $\begin{array}{c}\text { Tránsito y } \\
\text { el transporte } \\
\text { terrestre } \\
\text { dentro de su } \\
\text { circunscripción } \\
\text { cantonal; }\end{array}$ & $\mathrm{N} / \mathrm{C}$ \\
\hline $\begin{array}{l}\text { Actividades } \\
\text { productivas }\end{array}$ & $\begin{array}{c}\text { Actividades } \\
\text { productivas } \\
\text { regionales }\end{array}$ & $\begin{array}{l}\text { Actividades } \\
\text { productivas } \\
\text { provinciales, } \\
\text { especialmente } \\
\text { las } \\
\text { agropecuarias }\end{array}$ & $\mathrm{N} / \mathrm{C}$ & $\begin{array}{l}\text { Actividades } \\
\text { productivas } \\
\text { comunitarias }\end{array}$ \\
\hline Ambiental & $\begin{array}{c}\text { Fomentar } \\
\text { Seguridad } \\
\text { Alimentaria }\end{array}$ & $\begin{array}{l}\text { La gestión } \\
\text { ambiental } \\
\text { provincial }\end{array}$ & $\begin{array}{l}\text { - Depuración } \\
\text { de aguas } \\
\text { residuales, } \\
\text { manejo de } \\
\text { desechos } \\
\text { sólidos, } \\
\text { actividades de } \\
\text { saneamiento } \\
\text { ambiental } \\
\text {-Regular, } \\
\text { autorizar y } \\
\text { controlar la } \\
\text { explotación } \\
\text { de materiales } \\
\text { áridos y } \\
\text { pétreos, que se } \\
\text { encuentren en } \\
\text { los lechos de } \\
\text { los ríos, lagos, } \\
\text { playas de mar y } \\
\text { canteras }\end{array}$ & $\begin{array}{c}\text { Biodiversidad } \\
\text { y la } \\
\text { protección } \\
\text { ambiental }\end{array}$ \\
\hline
\end{tabular}


Rev. CAP Jurídica Central N. 4 - agosto 2019, ISSN 2550-6595

\begin{tabular}{|c|c|c|c|c|}
\hline Infraestructura & $\mathrm{N} / \mathrm{C}$ & $\mathrm{N} / \mathrm{C}$ & $\begin{array}{l}\text { Planificar, cons- } \\
\text { truir y mantener } \\
\text { la infraestruc- } \\
\text { tura física y los } \\
\text { equipamientos } \\
\text { de salud y } \\
\text { educación, así } \\
\text { como los espa- } \\
\text { cios públicos } \\
\text { destinados al } \\
\text { desarrollo so- } \\
\text { cial, cultural y } \\
\text { deportivo, de } \\
\text { acuerdo con la } \\
\text { ley. } \\
\text { - Preservar, } \\
\text { mantener y } \\
\text { difundir el } \\
\text { patrimonio } \\
\text { arquitectónico, } \\
\text { cultural y natu- } \\
\text { ral del cantón } \\
\text { y construir los } \\
\text { espacios públi- } \\
\text { cos para estos } \\
\text { fines }\end{array}$ & $\begin{array}{l}\text { - Los equi- } \\
\text { pamientos y } \\
\text { los espacios } \\
\text { públicos de la } \\
\text { parroquia } \\
\text { - Vigilar la } \\
\text { ejecución de } \\
\text { obras }\end{array}$ \\
\hline $\begin{array}{l}\text { Cooperación } \\
\text { Internacional }\end{array}$ & Sí & Sí & Sí & Sí \\
\hline
\end{tabular}




\begin{tabular}{|c|c|c|c|c|}
\hline Otras & $\begin{array}{l}\text { - Determinar } \\
\text { las políticas } \\
\text { de investiga- } \\
\text { ción e innova- } \\
\text { ción del cono- } \\
\text { cimiento } \\
\text { - Otorgar per- } \\
\text { sonalidad jurí- } \\
\text { dica, registrar } \\
\text { y controlar a } \\
\text { las organiza- } \\
\text { ciones socia- } \\
\text { les de carácter } \\
\text { regional; }\end{array}$ & $\mathrm{N} / \mathrm{C}$ & $\begin{array}{l}\text { - Gestionar los } \\
\text { servicios de } \\
\text { prevención, pro- } \\
\text { tección, socorro } \\
\text { y extinción de } \\
\text { incendios }\end{array}$ & $\begin{array}{l}\text { - Promover la } \\
\text { organización } \\
\text { de los ciuda- } \\
\text { danos de las } \\
\text { comunas, re- } \\
\text { cintos y demás } \\
\text { asentamientos } \\
\text { rurales con el } \\
\text { carácter de or- } \\
\text { ganizaciones } \\
\text { territoriales } \\
\text { de base }\end{array}$ \\
\hline
\end{tabular}

Elaboración propia

Fuente: Constitución Política de 2008, con su enmienda, COOTAD, con sus reformas del 2011.

En relación a las competencias exclusivas de la región es importante analizar que al no existir regiones estas competencias exclusivas siguen en manos del Gobierno Central, así pues, competencias como planificación, vialidad, tránsito, cuencas hidrográficas y agua aún no han sido materializadas. De esta manera, la descentralización en el nivel regional es un proceso que aún no ha iniciado. Las causas de este fracaso son correlativas a la falta de vectores (interés por competencias) que permitan la unión entre provincias y por ende establezcan spillovers o factores de derrame, los cuales produzcan efectos de cascada en cada una de las provincias.

En lo referente al siguiente nivel de gobierno, la provincia dispone de competencias importantes para el desarrollo del país en temas ligados a la planificación, vialidad en zonas rurales, riego ${ }^{41}$,

41 La competencia del riego genera conflictos interinstitucionales, puesto 
actividades productivas, agropecuarias, y gestión ambiental, sin embargo, la realidad no va de la mano con la atribución de recursos puesto que no se ha fortalecido la capacidad tributaria de los gobiernos provinciales en la generación de recursos propios.

En cuanto a los municipios, las competencias son mayores en relación a los otros niveles de gobierno, puesto que se consideraba que este nivel de administración pública disponía de una proximidad al ciudadano y sus problemas, por lo tanto, podría ser el interlocutor válido entre ciudadanía y Estado, así pues, las teorías de democracia deliberativa atribuyen a este tipo de GADs la posibilidad de estructurar política pública a partir de aportes del ciudadano común. En efecto, este nivel de gobierno ha obtenido la hegemonía de un poder local sobre los otros (CARRIÓN, p. 27). De esta manera, las relaciones de poder entre administración municipal y ciudadanía se enmarca en un proceso clientelar entre el cacique y sus favorecidos. En relación al proceso de descentralización, este nivel de gobierno dispone de mayores competencias, así como mayores recursos ${ }^{42}$ en relación a otros niveles de gobierno. De esta manera, cabe preguntarse si

que intervienen en este sector la Secretaría Nacional del Agua, el Ministerio de Agricultura, Ganadería, Acuacultura y Pesca, y los gobiernos provinciales, ademáselagua es un instrumento declientelismo político. Cifras del año 2009 señalan que: La población campesina e indígena cuenta con sistemas comunales de riego, representan, según el CNRH hoy SENAGUA, el 86\% de los usuarios, sin embargo solo tienen el 22\% del área regada $y$, lo que es más grave, únicamente acceden al 13\% del caudal, en tanto que el sector privado que representa el 1\% de la UPA's, concentra el 67\% del agua. (GAYBOR, p. 15).

42 A parte de ser partícipe del 67\% de la distribución de la totalidad de los GADs, se ven beneficiados de los impuestos: predial urbano y rural, vehículos, alcabalas, plusvalía, patente, 1.5 por mil, juegos, espectáculos públicos, materiales áridos y pétreos. 
estas competencias y recursos han servido para llevar bienestar a los ciudadanos o se han convertido en un espacio para fortalecer una carrera política a partir del clientelismo ${ }^{43}$.

En cuanto a las parroquias rurales la relación con los municipios es de orden clientelar porque al no contar con recursos suficientes para cumplir con las competencias enmendadas necesitan efectuar alianzas políticas para promover obras en beneficio de su comunidad. Si bien en un inicio el Consejo Nacional de Juntas Parroquiales surgió como un ente que permitía visibilizar desde la movilización hasta la aprobación de la norma, en la actualidad, este órgano no lleva los intereses de las parroquias hacia la arena política, y por tanto, a logros válidos para este nivel de gobierno.

\section{1. 2. Titularidad compartida con otros niveles de gobierno}

Las competencias concurrentes son aquellas cuya titularidad corresponde a varios niveles de gobierno en razón del sector o materia. Dentro de las competencias concurrentes se encuentra: el Registro de la Propiedad ejemplo expreso tanto en la norma constitucional como en el COOTAD que establece que esta competencia le corresponde al gobierno central (sistema nacional) y al gobierno municipal (sistema cantonal $^{44}$ que alimentará al sistema nacional).

43 Para constatar esta afirmación, cabe recolectar información sobre las diferentes reelecciones en estos niveles de gobierno y futuras elecciones en otros órganos de gobierno.

44 "El sistema público de registro de la propiedad será administrado de manera concurrente entre el Ejecutivo y las municipalidades." 
Otro ejemplo de competencia concurrente son los sectores estratégicos como se explicó ex ante. Finalmente, un ejemplo que no nace de una competencia exclusiva establecida en la CRE, 2008 ni el COOTAD es el ejercicio concurrente de actividades para la forestación y reforestación con fines de protección ambiental emitido por el Consejo Nacional de Competencias (CNC) a través de Resolución No. 007-CNC-2012.

\section{2. Competencias Adicionales y Residuales}

El CNC transfiere las competencias hacia los GADs de acuerdo a un proceso administrativo que determina el COOTAD, este procedimiento se estructura de varias fases; i) informes habilitantes donde se analiza el estado de la competencia y la capacidad operativa de los GADs, ii) Informe de la Comisión de $\mathrm{Costeo}^{45}$, donde se determina la capacidad de los GADs de asumir competencias, iii) si el GAD puede asumir la competencia, ésta es entregada a través de una Resolución del CNC, y posteriormente se habilitan recursos, en teoría no existe entrega de competencias sin recursos para su ejercicio, iv) si el GAD no puede asumir la competencia el CNC debe realizar el fortalecimiento institucional correspondiente, para que puedan los GADs asumir las competencias.

(Art. 265 CRE)

La administración de los registros de la propiedad de cada cantón corresponde a los gobiernos autónomos descentralizados municipales. El sistema público nacional de registro de la propiedad corresponde al gobierno central, y su administración se ejercerá de manera concurrente con los gobiernos autónomos descentralizados municipales... (Art. 142 COOTAD).

Un represente de la Entidad que entrega la competencia, un representante del SENPLADES, un representante del ministerio de Finanzas y tres representantes de los GADs que asumen la competencia. (Art. 123 COOTAD) 
Esta sucesión de fases permite comprender las competencias adicionales y residuales, las cuales son entregadas por el CNC hacia los GADs, cabe señalar que el CNC dispone también la potestad de emitir resoluciones que entregan competencias de orden exclusiva y concurrente.

En este orden de ideas, la definición de los dos tipos de competencias que la norma señala presenta una distinción puesto que, la diferencia reside en el principio de subsidiariedad ${ }^{46}$ y progresividad, los cuales están incluidos en la competencia adicional más no en la residual, ya que las adicionales devienen competencias que se añaden durante el proceso evolutivo de la descentralización, es decir el Estado se deslinda de ciertas prerrogativas con el fin de fortalecer los GADs y residuales no son parte de las competencias privativas del Estado, por lo tanto, son residuos de regulación que pueden ser entregados a los GADs.

46 El Art. 3 literal d) del COOTAD, 2010 establece una definición para el concepto de subsidiariedad. 
Tabla 4

Cuadro comparativo de competencias adicionales y residuales

\begin{tabular}{|c|c|c|}
\hline $\begin{array}{c}\text { Competencias } \\
\text { Adicionales }\end{array}$ & $\begin{array}{l}\text { Competencias } \\
\text { Residuales }\end{array}$ & Análisis \\
\hline $\begin{array}{l}\text { - Son parte de los } \\
\text { sectores o materias } \\
\text { comunes }\end{array}$ & $\begin{array}{l}\text { - No forman parte de } \\
\text { los sectores estraté- } \\
\text { gicos, competencias } \\
\text { privativas o exclu- } \\
\text { sivas del gobierno } \\
\text { central. }\end{array}$ & $\begin{array}{l}\text { Tanto las competencias } \\
\text { adicionales como } \\
\text { residuales formarían } \\
\text { parte de los sectores } \\
\text { comunes }\end{array}$ \\
\hline $\begin{array}{l}\text { - No están asignadas } \\
\text { expresamente por } \\
\text { la Constitución o } \\
\text { este Código a los } \\
\text { gobiernos autónomos } \\
\text { descentralizados } \\
\text { - Serán asignadas por } \\
\text { el Consejo Nacional } \\
\text { de Competencias }\end{array}$ & $\begin{array}{l}\text { - No están asignadas en } \\
\text { la Constitución o en } \\
\text { la ley a favor de los } \\
\text { gobiernos autónomos } \\
\text { descentralizados } \\
\\
\text { - Serán asignadas por } \\
\text { el Consejo Nacional } \\
\text { de Competencias. }\end{array}$ & $\begin{array}{l}\text { Se establece tanto } \\
\text { en las competencias } \\
\text { adicionales como } \\
\text { residuales que no están } \\
\text { de forma explícita en la } \\
\text { CRE ni en el COOTAD } \\
\text { y que las entrega el } \\
\text { Consejo Nacional de } \\
\text { Competencias }\end{array}$ \\
\hline $\begin{array}{l}\text { En base al principio } \\
\text { de subsidiariedad y } \\
\text { progresividad, que en la } \\
\text { norma es tratada como } \\
\text { una característica de la } \\
\text { descentralización. }\end{array}$ & $X$ & $\begin{array}{l}\text { La subsidiariedad } \\
\text { supone privilegiar la } \\
\text { gestión de los servicios, } \\
\text { competencias y } \\
\text { políticas públicas por } \\
\text { parte de los niveles de } \\
\text { gobierno más cercanos } \\
\text { a la población. }\end{array}$ \\
\hline
\end{tabular}

Fuente: COOTAD, 2010

Elaboración propia 
En todo caso, según Gustavo Bedón, las definiciones de competencias adicionales y residuales no son conceptos materiales sino referenciales relacionados con la progresividad por fases para la transferencia de competencias (p. 221), que se explicó al inicio de este punto.

Tabla 5

Plazo de entrega de transferencias de competencias

\begin{tabular}{|l|c|}
\hline Competencia & Plazo Máximo \\
\hline Nuevas Exclusivas Constitucionales & 0 a 4 años \\
\hline Adicionales / sectores de alta descentralización & 4 a 8 años \\
\hline Residuales & Permanente \\
\hline
\end{tabular}

Fuente: Planificación del Desarrollo y Ordenamiento Territorial.

En este marco es importante señalar que el CNC no ha entregado ninguna competencia adicional, ni residual a los GADs, porque se encuentran aún en proceso de entrega de competencias exclusivas a los gobiernos locales. 


\section{CONCLUSIONES}

En lo referente a la organización territorial, el proceso de descentralización está en vía de construcción, en efecto, la voluntad política es parte principal del andamiaje que permitirá construir regiones, de esta manera, sin la constitución de regiones, las competencias de este nivel de gobierno siguen en manos del gobierno central y por ende no ha existido un proceso de descentralización en este nivel de gobierno.

En cuanto a los DM y CTT como regímenes especiales se observa que están normadas pero aun no se materializan, porque no se han constituido por requisitos legales y voluntad política del GAD municipal como es el caso de los DM o por trabas normativas que impiden la conformación de los CTT. En consecuencia, las competencias y recursos no se deslindan del Estado Central y de los otros niveles de gobierno.

En el Plan Nacional de Descentralización, elaborado por el Consejo Nacional de Competencias 2012-2015, se propuso transferir e implementar el 100\% de las competencias exclusivas hasta el año 2015, meta que no se ha cumplido hasta la actualidad, puesto que el proceso de descentralización es un continuum, más su dinámica no está supeditada a un plazo específico.

No se han transferido competencias adicionales ni residuales a los GADs, puesto que aún no se concluye el proceso de transferencia de las competencias exclusivas. El Estado no se ha deslindado de competencias sino que existe una tendencia a la re-centralización.

El Estado Central ha buscado ser un Estado fuerte en los últimos años debido a su concepción ideológica de desarrollo basado en 
Karina Tello Toral

DESCENTRALIZACIÓN EN ECUADOR

Giovany LuCiO ¿UN PROCESO INCONCLUSO?

una inversión desde lo público y a una demanda estructurada desde el Estado. 
Rev. CAP Jurídica Central N. 4 - agosto 2019, ISSN 2550-6595

\section{BIBLIOGRAFÍA}

BARRERA, Augusto (coord.). Ecuador un modelo para (des) armar, descentralización, disparidades y modelo de desarrollo. Quito, Centro de Investigaciones Ciudad, 1999.

BEDÓN, Gustavo. La Nueva Organización Territorial y el Nuevo Modelo de Descentralización en el Ecuador: Descentralización y Sistema Nacional de Competencias en el nuevo ordenamiento jurídico ecuatoriano. Quito, Corporación de Estudios y Publicaciones, 2012.

CARRIÓN, Fernando. La descentralización en el Ecuador de hoy: sus alternativas. Revista Íconos. Quito, FLACSO, 2008.

CÓDIGO ORGÁNICO DE ORGANIZACIÓN TERRITORIAL, AUTONOMÍA Y DESCENTRALIZACIÓN. Registro Oficial de la República del Ecuador N. . 303, Quito, 19 de octubre de 2010.

CONSTITUCIÓN DE LA REPÚBLICA DEL ECUADOR. Decreto Legislativo N. ${ }^{\circ}$ 000, Registro Auténtico. Quito, 13 de agosto de 1835. <https://www.cancilleria.gob.ec/wpcontent/uploads/2013/06/constitucion_1835.pdf>

CONSTITUCIÓN DE LA REPÚBLICA DEL ECUADOR. Decreto Supremo N. ${ }^{\circ}$ 000. Registro Oficial de la República del Ecuador N. ${ }^{\circ} 800$. Quito, 27 de marzo de 1979. <https:// www.cancilleria.gob.ec/wp-content/uploads/2013/06/ constitucion_1978.pdf> 
CONSTITUCIÓN DE LA REPÚBLICA DEL ECUADOR. Registro Oficial de la República del Ecuador N. ${ }^{\circ}$ 449. Quito, 20 de octubre de 2008.

CONSTITUCIÓN DE LA REPÚBLICA DEL ECUADOR. Registro Oficial N. 1 . Quito, 11 de agosto de 1998.

CONSTITUCIÓN DE LA REPÚBLICA DEL ECUADOR. Codificación de 1996. Ley N. ${ }^{\circ}$ 000. Registro Oficial de la República del Ecuador N. ${ }^{\circ} 969$. Quito, 18 de junio de 1996.

CONSTITUCIÓNDE LA REPÚBLICA DELECUADOR. Quito, 23 de septiembre de 1830._https://www.cancilleria.gob.ec/wpcontent/uploads/2013/06/constitucion_1830.pdf>https:// www.cancilleria.gob.ec/wp-content/uploads/2013/06/ constitucion_1830.pdfhttps://www.cancilleria.gob.ec/ wp-content/uploads/2013/06/constitucion_1830.pdf.

CONVENCIÓN PARA LA PROTECCIÓN DEL PATRIMONIO MUNDIAL, CULTURAL Y NATURAL DE 1972. Instrumentos Normativos. Organización de las Naciones Unidas para la Educación, la Ciencia y la Cultura (UNESCO). Página web: <http://portal.unesco. org/es/ev.php-URL_ID=13055\&URL_DO=DO_ TOPIC\&URL_SECTION=201.html $>$.

DICTIONNAIRE DE L'HISTOIRE DE FRANCE. Unes effigie omnipresente. Larousse, 2005. Web page: < http:// www.larousse.fr/archives/histoire_de_france/page/194>. 
Rev. CAP Jurídica Central N. 4 - agosto 2019, ISSN 2550-6595

ENMIENDAS A LA CONSTITUCIÓN DE LA REPÚBLICA DEL ECUADOR. Suplemento del Registro Oficial N. 653. Quito, Ediciones Legales, 2016.

GAYBOR, Antonio. Acumulación Capitalista en el campo y despojo del agua. 1. edición. Quito, Foro de los Recursos Hídricos, Simposio dirigido por CEDLA - Universidad de Ámsterdam, 2010.

LEY ORGÁNICA DE RÉGIMEN ESPECIAL DE LA PROVINCIA DE GALÁPAGOS. Registro Oficial de la República del Ecuador N. ${ }^{\circ}$ 520, Quito, 11 de junio de 2015.

LEY ORGÁNICA DEL DISTRITO METROPOLITANO DE QUITO. Registro Oficial de la República del Ecuador N. 345. Quito, 27 de diciembre de 1993.

MORAleS, Marco. La Nueva Organización Territorial y el Nuevo Modelo de Descentralización en el Ecuador. Quito, Corporación de Estudios y Publicaciones, 2012.

OLEAS Montalvo, Julio. "Ecuador 1980-1990: crisis, ajuste y cambio de régimen de desarrollo", América Latina en la historia económica. Scielo, abril de 2017. Página web: < https://dx.doi.org/10.18232/alhe.v24i1.724>.

ORTIZ, Santiago, (coord.). Balance de la Descentralización en el Ecuador: 1998-2016. Quito, Editorial Corporación Alemana, 2017. Página web: <http://www.amevirtual. gob.ec/wp-content/uploads/2018/01/Balance-de-laDescentralizacion-en-Ecuador-2017.pdf $>$. 
Plan NACIONAL DE DESCENTRALIZACIÓN. Resolución N. ${ }^{\circ}$ 003-CNC-2012, Registro Oficial de la República del Ecuador N. ${ }^{\circ}$ 673. Quito, 30 de marzo de 2012.

RENAUD, Epstein. Gouverner à distance: Quand l'Etat se retire des territoires. Paris, Editions Esprit, 2006.

RESOLUCIÓN No. 007-CNC-2012, Suplemento del Registro Oficial de la República del Ecuador N. 727 , Quito, Ecuador, 19 jun. 2012.

SuING, José. Gobiernos Autónomos Descentralizados. Quito, Corporación de Estudios y Publicaciones, 2012.

. Derecho Municipal. Quito, Corporación de Estudios y Publicaciones, 2017.

SENPLADES. LINEAMIENTOS PARA LA PLANIFICACIÓN DEL DESARROLLO Y EL ORDENAMIENTO TERRITORIAL: estrategias para el fortalecimiento del Sistema Nacional Descentralizado de Planificación Participativa. Quito, 2010.

VICIANO, Pastor. "Algunas consideraciones sobre la organización territorial del Estado", Andrade, Santiago, Grijalva, Agustín, y Storini, Claudia. (edits.). La nueva Constitución del Ecuador. Estado, derechos e instituciones. Quito, Corporación Editora Nacional, 2009.

VILLAVICENCIO, Gaitán. "Gobiernos seccionales en Ecuador: estatismo y estatalidad en crisis (1998-2009)" , Revista 
Rev. CAP Jurídica Central N. 4 - agosto 2019, ISSN 2550-6595

de Ciencias Sociales y Humanas. Quito, Ecuador Universitas, 2010.

\section{NOTA}

Una tendencia a re-centralizar justamente es la competencia de infraestructura de educación y salud puesto que con las enmiendas a la Constitución de 2015, el Gobierno Central retomó esta competencia y a los GADs municipales se condiciona la realización de infraestructura de educación y salud previa autorización del Ente rector. Así el artículo reformado establecía: "Planificar, construir y mantener la infraestructura física y los equipamientos de los espacios públicos destinados al desarrollo social, cultural y deportivo". Sin embargo, con la declaratoria de inconstitucionalidad formal de las Enmiendas Constitucionales del 2015, la competencia de infraestructura de educación y salud retorna a los gobiernos autónomos descentralizados. 